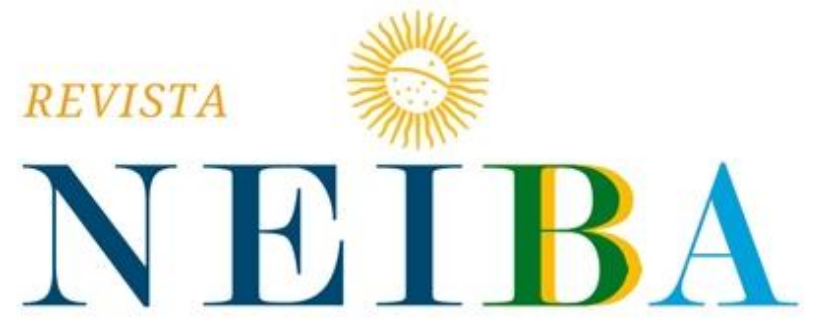

CADERNOS ARGENTINA-BRASIL

Volume 9, 2020, p. 01-19

DOI: 10.12957/neiba.2020.47941|e47941|ISSN: 2317-3459

\title{
AS SEMELHANÇAS ENTRE OS GOVERNOS TEMER E BOLSONARO NA POLÍTICA EXTERNA (2016-2019)
}

THE SIMILARITY BETWEEN THE GOVERNMENTS TEMER AND BOLSONARO IN FOREIGN POLICY (2016-2019)

\section{Danilo Sorato Oliveira Moreira ${ }^{1}$}

${ }^{1}$ Universidade Federal do Amapá (UNIFAP), Macapá, AP, Brasil. E-mail: danilosorato@hotmail.com ORCID: https://orcid.org/0000-0001-8438-3579

Recebido em: 24 jan. 2020 | Aceito em: 29 jan. 2020. 


\section{RESUMO}

A Política Externa Brasileira do ultimo triênio (2016-2019) é marcada por mudanças em relação ao período anterior do Partido dos Trabalhadores (PT). Assim, o objetivo desse artigo é apontar essas alterações através da continuidade entre os governos Temer e Bolsonaro nas áreas de desideologização, comércio e segurança. Para cumprir essa finalidade, a metodologia é a análise bibliográfica, as notas do Itamaraty e documentos oficiais. Portanto, argumenta-se que no período assinalado, a ação internacional brasileira é pautada pela crítica aos parceiros Sul-Sul, além da defesa de agendas como a busca de acordos comerciais e investimentos, bem como a ampliação do debate sobre o combate aos crimes transnacionais nas fronteiras brasileiras.

Palavras-chave: Política Externa Brasileira, Temer, Bolsonaro.

\section{ABSTRACT}

The Brazilian Foreign Policy of the last three years (2016-2019) is marked by changes in relation to the previous period of the Workers' Party (PT). Thus, the objective of this article is to point out these changes through continuity between the Temer and Bolsonaro governments in the areas of desideologization, trade and security. To fulfill this purpose, the methodology is bibliographic analysis, Itamaraty notes and official documents. Therefore, it is argued that in the period indicated, Brazilian international action is guided by criticism of South-South partners, in addition to the defense of agendas such as the search for trade agreements and investments, as well as the expansion of the debate on the fight against transnational crimes on Brazilian borders.

Keywords: Brazilian foreign policy, Temer, Bolsonaro. 


\section{INTRODUÇÃO}

A vitória nas Eleições presidenciais do candidato do Partido Social Liberal (PSL), Jair Bolsonaro, sobre o candidato do Partido dos Trabalhadores (PT), Fernando Haddad, iniciou uma série de projeções acerca da Política Externa a ser adotada pelo novo governo na imprensa brasileira (Ruic, 2018). A proposta do artigo é analisar os principais aspectos da administração Michel Temer (2016-2018) e Jair Bolsonaro (2019) para apontar que existe um grande espaço para continuidades na agenda exógena entre os dois governos, especialmente em temas como a desideologização, o comércio e a segurança. Portanto, em uma análise de Política Externa, que envolva a compreensão de discursos oficiais de chanceleres e presidentes, e documentos oficiais, entende-se que os próximos passos da nova gestão estão em semelhança com as mudanças implantadas com a "Nova Política Externa Brasileira" a partir de maio de 2016. Esses novos modelos pretendem, sobretudo, diferenciar-se das administrações anteriores de Lula da Silva e Dilma Rousseff para a impressão de uma nova marca (Sorato, 2019, p. 17).

A Política Externa Brasileira ao longo dos últimos 200 anos esteve condicionada às alterações de turno dos chefes de Estado, mas se manteve uma característica intrínseca, a impossibilidade de provocar conflitos internacionais, salvo no período entre 1850-1870 na região do Prata. Na República, portanto, como apontam Cervo e Bueno (2015, p. 13), além da sua condição constitucional de impedir a guerra, os homens de estado estiveram em busca do interesse nacional sob duas formas, o desenvolvimento econômico e a autonomia. Nesse processo macro, com 130 anos de existência (1889-2019), ora os tomadores de decisão lograram atender às vontades globais socioeconômicas, ora fizeram políticas mais restritivas e prejudiciais ao país.

No que tange a Nova República (1985-2019), pode-se afirmar que a Política Externa Brasileira mantém traços de continuidade na sua ação externa. Como dizem Cervo e Bueno (2015, p. 488-489), a busca pelo desenvolvimento e pela autonomia é articulada por três conceitos na condução do Estado brasileiro em ambiente externo que são: o Estado desenvolvimentista, o Estado normal e o Estado logístico. O primeiro deles utiliza a força estatal para buscar maior liberdade e nacionalidade, no Brasil funciona 
com relativa estabilidade entre 1930 a 1985; O segundo deles, usa-se a força privada com subserviência ao capital estrangeiro, no modelo brasileiro encaixa-se nos governos Collor (1990-1992), Itamar (1992-1994) e FHC (1995-2002); e o terceiro deles, articula o núcleo nacional com empreendedorismo social na busca por uma inserção mais madura na ordem global, no país ocorre com maior frequência nos governos Lula (2003-2010) e Rousseff (2011-2016).

Com o processo de impedimento articulado em 2016 no Brasil, a Política Externa passa por um momento de questionamento na busca de outro modelo de inserção internacional sob a liderança de atores políticos diferentes ao PT, são os casos dos governos de Temer e de Bolsonaro. Entretanto, diferente do que a maioria dos analistas identifica, esse artigo pretende revelar essas alterações, mas buscando a intenção de mostrar os elementos de continuidade entre esses dois governos no triênio 2016-2019.

A Política Externa Brasileira do ultimo triênio (2016-2019) é marcada por é marcada por mudanças em relação ao período anterior do Partido dos Trabalhadores (PT). Assim, o objetivo desse artigo é apontar essas alterações através da continuidade entre os governos Temer e Bolsonaro nas áreas de desideologização, comércio e segurança. Assim, o objetivo desse artigo é apontar os aspectos de continuidade entre os governos Temer e Bolsonaro. Para cumprir essa finalidade, a metodologia é a análise bibliográfica, as notas do Itamaraty e documentos oficiais. Portanto, argumenta-se que no período assinalado, a ação internacional brasileira é pautada pela crítica aos parceiros Sul-Sul, além da defesa de agendas como a busca de acordos comerciais e investimentos, bem como a ampliação do debate sobre o combate aos crimes transnacionais nas fronteiras brasileiras.

$\mathrm{Na}$ primeira seção são discutidos os elementos teóricos e bibliográficos. Em primeiro lugar, a base conceitual que solidifica o trabalho por meio da Análise de Política Externa, cujo foco é fazer uma diferença entre desideologização, ideologização e ideologia na Externa. Em diálogo com autores internacionais e nacionais, esse conceito-chave é fundamental para a compreensão dos processos que envolvam a construção de uma Política Externa. 
A segunda seção chamada tem como objetivo analisar as principais ações de PEB do período elencado, sobretudo, nos discursos e notas do Itamaraty apresentados pelos chanceleres. Na primeira parte, apresenta-se como se formula a administração Serra, especialmente como a pioneira em criar novos caminhos através da "Nova Política Externa Brasileira". Na segunda parte, debate-se como ocorre a administração Nunes, no qual são aprofundados os aspectos de Ideologização, Economia e Segurança iniciados pelo antecessor. Por fim, na terceira parte, apresenta-se como acontece a administração Araújo, em que são remarcados os objetivos centrais nos temas de Ideologização, Economia e Segurança, portanto, um caminho de continuidade em relação aos Ministros de Relações Exteriores, mas com novas ações de PEB.

\section{A ANÁLISE DE POLÍTICA EXTERNA BRASILEIRA}

A Análise de Política Externa é um campo consolidado na área de Relações Internacionais. Ela visa, entre muitos objetivos, como dizem Salomón e Pinheiro (2013, p. 40), estudar a política externa de governos próprios, com observância em seus determinantes, finalidades, tomada de decisões e a ação efetivamente realizada. Inclusive, para entender essas dinâmicas próprias e correntes que de forma metodológica sejam analisados discursos oficiais dos chanceleres e presidentes, documentos oficiais, acordos comerciais, dentre outros instrumentos metodológicos.

O autor português (2015, p. 130) aponta os principais debates paradigmáticos do campo de Análise de Política Externa. A abordagem tradicional, até meados de 1950, é de que a Política Externa é um local em que os estados atuam na luta pelo poder em sentido realista. Portanto, em dois caminhos, há um centro da análise no ator internacional estatal, ademais de uma distinção binária entre ambiente externo e interno. O ente estatal centra suas ações na agenda de segurança e defesa, algo ainda perceptível na PEB, mesmo que com menor ênfase, esse tema tem recuperado protagonismo desde a assunção de Michel Temer e o discurso de Serra em maio de 2016, acerca da preocupação com os crimes transnacionais nas díades brasileiras.

A abordagem científica, a partir dos anos de 1950, desenvolvida nos Estados Unidos, especialmente com Snyder, Bruck e Sapin, é responsável pela ampliação da APE. Há um olhar mais voltado para a tomada de decisão dos agentes políticos dentro 
dos estados (foreign policy decision-making). Assim, destaca-se a atitude e comportamento desses personagens em seus ambientes internos, em outras palavras, ao contrário do modelo anterior, existe uma análise mais específica em torno do contexto interno desses agentes.

A problemática da racionalidade em APE, defendida pelos economistas intenta compreender as etapas do processo decisório de forma utilitária, quer dizer, quando o agente busca aproveitar ao máximo seus benefícios, à medida que tenta diminuir seus prejuízos. Desse paradigma, enfatizam-se os estudos de Alison (citado por Mendes, 2015, p. 135), em que subdivide os paradigmas em modelos clássicos, processo organizacional e política burocrática. No primeiro, mais uma vez prevalece o olhar estatal do interesse nacional e da agenda de segurança. No segundo, a organização estatal em grupos diferentes e distantes com suas próprias rotinas e processos em política externa. E no terceiro, as organizações políticas disputando seus espaços em uma espécie de jogo, em que a competição entre os agentes determina o caminho a seguir na ação internacional.

A problemática dos fatores ideológicos e perceptivos em APE demarca como os tomadores de decisões escolhem suas posições a partir de uma imagem particular que possuem das situações reais. Em outras palavras, cada decisor apresenta um olhar subjetivo sobre o fato, o que inviabiliza a perspectiva da objetividade em Política Externa. Esse debate proposto por Boulding (apud Mendes, 2015, p. 138) é fundamental nesse artigo, pois existe uma discussão nas gestões Temer e Bolsonaro acerca de uma possível ideologização da PEB em seus antecessores entre 2003-2016. Assim, os novos decisores na figura dos presidentes, Temer e Bolsonaro, além dos Ministros, Serra, Nunes e Araújo, defendem o afastamento de ideias partidárias e ideológicas na agenda internacional. Para tal, afastam-se dos parceiros estratégicos do PT, como Venezuela, Cuba e Nicarágua, e se deslocam para os Estados Unidos, Europa Ocidental, Israel, etc. Entretanto, como diz Mendes (2015), a perspectiva ideológica e perceptiva, defende que não existem tomadores de decisão objetivos e sem ideologia, mas sim com ideias que se formam em cada mente de forma particular. Portanto, o 
conceito de desideologização usado na retórica dos governos Temer e Bolsonaro se tornam vazios em virtude da efetiva ideologia que possuem em suas escolhas.

É fundamental citar o conceito de desideologização como uma construção recente pelos formuladores de Política Externa. Como debate Echaide (2016), esse termo é utilizado pela primeira vez com a chanceler de Mauricio Macri na Argentina em 2015. No cenário do país vizinho, a direita liberal argentina procura se opor aos grupos de esquerda que estavam no poder, caso de Cristina Kirchner. Assim, na agenda internacional se fez necessário se distanciar da Venezuela e países bolivarianos.

No Brasil, pode-se perceber que a instrumentalização desse discurso é usada pelos grupos de oposição ao PT ao criticarem a sua ação internacional entre 2002-2016. Por exemplo, já nas Eleições de 2014 a desideologização aparece nos discursos do programa de governo do então candidato presidencial, Aécio Neves (PSDB) e seu vice, Aloysio Nunes. A desideologização era uma pauta do PSDB contra o PT naquela conjuntura eleitoral. Depois, já com a composição pós-Impeachment, a articulação PMDB-PSDB garante o Ministério das Relações Exteriores aos tucanos que enfim conseguem implantar institucionalmente suas ideias na Política Externa Brasileira (Neves; Nunes, 2014, p. 52).

Além disso, outro aspecto importante é diferenciar o uso de alguns termos como desideologização e ideologia na Política Externa. Como já demonstrado, o primeiro termo se refere há uma suposta neutralidade na Política Externa brasileira defendida pelos grupos de posição ao PT.

Por outro lado, a ideologia na Política Externa é uma categoria analítica que demarca bem como os tomadores de decisão possuem ideologias ao tomarem as suas decisões. Nesse sentido, utiliza-se o trabalho de Mendes (2015) para mostrar que não existe ação internacional sem ideologia. A partir disso, o artigo diverge dos discursos utilizados pelos governos Temer e Bolsonaro quando assumem a desideologização enquanto agenda de Política Externa. Essas duas administrações se amparam em escolhas, como por exemplo, o distanciamento dos países aliados do PT (Venezuela, Bolívia, Cuba) e a aproximação com países ocidentais e tradicionais (EUA, Europa, Israel). 
Por fim, a abordagem eclética defendida por Mendes (2015, p. 140), marcada pela apreensão empírica e conceitual. Ela se ampara em três fatores para a análise, o ambiente externo, o ambiente interno e o ambiente ideológico e perceptivo. Então, de forma mais plural e heterodoxa, encontra-se um paradigma que contempla diversos sentidos e direções da Política Externa. Nesse artigo, compreende-se que a abordagem eclética seja a mais adequada para o estudo pela possibilidade de coadunar fatores exógenos, endógenos e ideológicos-perceptíveis sobre a gestão Temer e Bolsonaro no Brasil.

\section{A NOVA POLITICA EXTERNA BRASILEIRA: O PROCESSO DE CONTINUIDADE ENTRE OS GOVERNOS TEMER E BOLSONARO}

A continuidade entre os governos Temer e Bolsonaro em Política Externa se dá pela prioridade em temas da agenda como a desideologização, o comércio e a segurança. Apesar da mudança dos Chanceleres do Ministério das Relações Exteriores (MRE), com personalidades e características diferentes, tanto José Serra (2016-2017), quanto Aloysio Nunes (2017-2018) e Ernesto Araújo (2019-) mantém discursos, ações e estratégias similares nesses três eixos de Política Externa Brasileira.

O afastamento da presidente, Dilma Rousseff, após o processo de Impeachment em maio de 2016, possibilita a assunção em seu lugar do então vice-presidente, Michel Temer. Ao assumir, o novo presidente, começa delimitar a Política Externa em seu discurso de posse no Congresso Nacional. Para o público seleto de Deputados e Senadores, inicia com uma arguição acerca dos princípios constitucionais de relações internacionais do país. Para logo em seguida, repetir o mesmo discurso na cerimônia de posse dos novos Ministros em 12 de maio de 2016. Importante destacar a seguinte passagem:

[...] São, meus amigos, esses elementos de consenso que nos permiti estabelecer bases sólidas para a política externa que volte a representar os valores e interesses permanentes no nosso País. A recuperação do prestígio do País e da confiança em seu futuro serão tarefas iniciais e decisivas para o fortalecimento da inserção internacional da nossa economia. [...] (Temer, 2016) 
Após intentar dar um ar de legitimidade a condução externa citando os princípios constitucionais e a sua própria participação na feitura na Assembleia Constituinte, o responsável pela implementação da PEB defende que o Estado brasileiro deve recuperar os valores e interesses nacionais. Nessa ideia, ainda que embrionária, já existe uma necessidade para se diferenciar das administrações anteriores que com a fala de José Serra logo abaixo, solidifica-se pela ideia de "desideologização" da PEB. Ademais, o então presidente, dá mais uma pista para a prioridade da sua ação externa, quer dizer, pensar como o país pretende levar sua economia ao mundo. Aqui, através da prioridade na pauta comercial, o Brasil temerista busca acertar parcerias externas que tragam benefícios econômicos. (Souza; Souza; Oliveira, 2016)

Após seus primeiros discursos, o presidente em exercício, Michel Temer, designa para o Ministério das Relações Exteriores (MRE), José Serra. A escolha em seu início já é uma mudança em relação às administrações de Lula da Silva (2003-2010) e Rousseff (2010-2016), pois aponta para o cargo uma pessoa que não é do quadro da carreira do Itamaraty, algo impensado nas gestões do Partido dos Trabalhadores (PT).

Em seu primeiro pronunciamento oficial, José Serra, intitula a PEB como A Nova Política Externa Brasileira. Ele tece dez diretrizes para que a recém administração empossada se diferencie da gestão anterior com "[...] olhos voltados para o futuro e não para os desacertos do passado." (Serra, 2016). No conglomerado de princípios, destaca-se a primeira, a décima e a "décima primeira", como caminhos de continuidade com a nova administração de Jair Bolsonaro. Essa opção, desde já, não indica uma completa continuação entre os estilos de PEB, mas sim define um prisma a ser observado, inclusive, existem espaços de análise para apresentar as possíveis diferenças entre os períodos.

A primeira diretriz fala sobre o princípio da desideologização na Política Externa, com o afastamento de parceiros "não tradicionais", ou bolivarianos, como Venezuela, Bolívia, Cuba, etc. E a progressiva mudança para parcerias bilaterais tradicionais como Estados Unidos, Europa Ocidental, dentre outros. Ademais, são feitas ações efetivas, por exemplo, com a defesa pelo governo brasileiro do afastamento da Venezuela de 
organismo internacionais como o MERCOSUL, a Organização dos Estados Americanos e a União das Nações Sul-Americanas.

A décima diretriz se refere a prioridade em temas comerciais na Política Externa. A captação de investimentos e a produção de acordos comerciais, tornam-se o elemento principal da diplomacia brasileira. Sob a gestão Serra, são articuladas diversas iniciativas, especificamente com o México.

A "décima primeira diretriz" retoma o tema de segurança nas fronteiras brasileiras e o combate aos crimes transnacionais, como a venda ilegal de drogas e armas. Esse tema estava esquecido na agenda brasileira desde os anos de 1990, mas volta a ser pensado especialmente como elemento necessário de parcerias com países limítrofes como Bolívia, Paraguai, Venezuela, Colômbia, etc.

A saída de José Serra do cargo de Chanceler, não impossibilita que o seu programa sobre A Nova Política Externa Brasileira seja aprofundado pelo substituto, Aloysio Nunes. Em março de 2017, o presidente Michel Temer escolhe um novo Chanceler. Com a mesma atuação parlamentar e política que Serra, Aloysio Nunes é escolhido para diminuir as críticas ao antecessor, sobretudo cem relação aos problemas técnicos em assuntos de Política Externa.

O novo ministro tem uma atuação destacada nos últimos anos na Comissão de Relações Exteriores e Defesa Nacional do Senado Federal (CREDN), onde exerceu a presidência no biênio 2015-2016. Nesse espaço teve conhecimento de muitos temas que cercam a PEB, especialmente a relação com os EUA, a China, o MERCOSUL e a Venezuela.

Ao receber o cargo de José Serra, o novo Chanceler aponta as linhas maestras de sua condução na PEB que coincidem com seu antecessor. Em termos de desideologização, reafirma as ideias de Nova Política Externa Brasileira ao dizer que:

[...] Reafirmo o que tem sido dito desde o início do governo Temer: a política externa tem que estar a serviço do País e não dos objetivos de um partido, qualquer que seja ele. Não posso deixar de lembrar a preocupação, cada vez mais presente, com a escalada autoritária do governo venezuelano, que nos últimos anos esteve presente entre os grandes temas em debate. [...] (Nunes, 2017) 
Ele deixa claro que a continuidade é uma marca da sua gestão ao alinhar o princípio de "desideologização" ao caso da Venezuela, onde tem um protagonismo crescente na agenda de PEB.

Além de dar prosseguimento ao afastamento da Venezuela do MERCOSUL, Nunes é responsável pela criação e articulação do Grupo de Lima em agosto de 2017. Atualmente, é essa concertação de 14 países latino-americanos que vem tentando retirar o presidente da Venezuela, Nicolas Maduro, inclusive, com um papel protagonista do atual Chanceler de Bolsonaro, Ernesto Araújo.

A manutenção da ideologização se soma a prioridade nos temas de comércio na Política Externa. Nunes consegue articular diversas negociações para o início de novos acordos comerciais, tais como, Canadá, Singapura, Coreia do Sul, Colômbia e Associação Europeia de livre Comércio (EFTA). Essas ações se somam a assinatura do acordo de livre comércio com o Chile em novembro de 2018.

Por fim, na questão de segurança nas fronteiras é criado em maio de 2018, um setor administrativo no Ministério das Relações Exteriores do Brasil, para cuidar do assunto junto com os países que fazem fronteira. Além disso, em âmbito bilateral foram acertados nos acordos contra o crime transnacional, como por exemplo, com o Paraguai e a Bolívia.

A mudança de governo em 2019 com a eleição de Jair Bolsonaro em muitos sentidos são percebidas como um processo de ruptura da Política Externa Brasileira, tal como o próprio presidente previu ainda em campanha. Ou ainda como alguns analistas argumentam ao falar sobre o governo Bolsonaro. (Freixo, 2019).

Como defende Almeida (2019), a Política Externa de Bolsonaro é caracterizada pela ruptura nos procedimentos diplomáticos, especialmente se comparada com a tradição do Itamaraty nos últimos 30 anos. Essa análise do autor é importante, pois destaca a opinião de um especialista que fala com conhecimento de causa da instituição, ainda que marcado pelas disputas internas dos grupos pela condução do MRE ${ }^{1}$. Entretanto,

\footnotetext{
${ }^{1}$ Ao longo do tempo, construiu-se uma imagem do corpo diplomático brasileiro homogeneizada em torno dos valores profissionais e interesses brasileiros no exterior. Entretanto, esse desenho não evita que existam disputas internas entre os próprios funcionários do Itamaraty. Assim, classificam-se em dois grupos: os autonomistas e os institucionalistas pragmáticos. O primeiro grupo, cerca do PT, analisa-se a inserção internacional do país a partir de uma lógica Sul-Sul, com mais visão universalista e diversas nas parcerias internacionais, ademais de um foco no
} 
nesse artigo, entende-se que nos temas de ideologização, comércio e segurança, os caminhos se cruzam e são semelhantes entre a administração atual e anterior.

Com a assunção do presidente Bolsonaro em 1 de janeiro de 2019, a Política Externa Brasileira inicia um novo percurso, mas com alguns apontamentos de suas posições e estratégias analisados nos parágrafos anteriores. Assim, o novo chefe do Executivo defende em seu discurso para o Congresso Nacional sobre a PEB: "[...] A política externa retomará o seu papel na defesa da soberania, na construção da grandeza e no fomento ao desenvolvimento do Brasil [...]" (Bolsonaro, 2019a). Na sua fala, ele apenas revela alguns princípios de orientação do seu programa de ação externa como a soberania, sem levar em conta os assuntos trabalhados nesse artigo. Porém, em um momento anterior desse mesmo recado aos Parlamentares, Jair Bolsonaro, agrega duas facetas já percebidas na Gestão Temer: economia e desideologização. Ele diz assim: "[...] Precisamos criar um círculo virtuoso para a economia que traga a confiança necessária para permitir abrir nossos mercados para o comércio internacional, estimulando a competição, a produtividade e a eficácia, sem o viés ideológico. [...]" (grifo nosso, Bolsonaro, 2019a).

Esse discurso traduz a manutenção da ideia de desideologização na Política Externa pretendida pela nova administração, isto é, não possuir ideologia na agenda internacional. Assim como Temer, o governo Bolsonaro usa uma aparente neutralidade ideológica para se afastar de parceiros considerados socialistas e aliados do PT, tais como Venezuela, Cuba, Bolívia, etc. No lugar deles, a retórica desses governos defendem um retorno aos parceiros "tradicionais" e ocidentais, como EUA, Europa ocidental, Israel, dentre outros.

Além disso, na citação destacada em grifo, aparece outra coincidência de prioridade entre os governos Temer e Bolsonaro que é centralizar as ações na diplomacia econômica. Nesse ponto, argumenta-se que o Brasil deve procurar

projeto desenvolvimentista econômico. Nesse grupo, destacam-se Celso Amorim, Samuel Pinheiro Guimarães, etc; O segundo grupo, próximos de FHC e das legendas políticas do PSDB e DEM, identifica-se com uma inserção internacional liberalizante e com a manutenção da participação nos foros multilaterais de forma prática, além disso, defendem princípios como o universalismo, a autonomia e ideia de grandeza. Nesse agrupamento, os nomes de destaque são os de Celso Lafer, Nelson Barbosa, Paulo Roberto de Almeida, Luiz Felipe Lampreia, dentre outros. (Saraiva, 2010) 
investimentos e acordos comerciais na sua ação internacional para superar seus problemas econômicos internos.

Por fim, nesse discurso, o atual presidente apenas não falou no tema de segurança nas fronteiras, algo que é feito na sua segunda mensagem ao público, quando abre os trabalhos no Congresso Nacional em fevereiro de 2019.

Em mensagem ao Congresso Nacional na abertura da sessão legislativa, foram colocadas as principais ações de PEB no período anterior, mas também as perspectivas do governo Bolsonaro para os próximos quatro anos. Nesse documento oficial, na seção chamada, Brasil: Nação Forte, são divididos os assuntos de política externa dessa forma: 1) assuntos estratégicos prioritários, 2) diplomacia bilateral e multilateral, 3) integração regional, 4) comércio exterior e diplomacia econômica, 5) comunidades brasileiras no exterior e temas migratórios, 6) cooperação internacional e 7) segurança, defesa e inteligência. Apesar de ser descrito em toda a seção, de forma mais específica, a última parte é aquela que toca em temas de segurança e fronteira, inclusive com um tópico dedicado a esse fim.

Nesse tópico, de forma diferente aos outros assuntos de PEB, são dedicados de maneira densa, seis páginas para tratar das ações implementadas pela gestão Temer, e principalmente das perspectivas pensadas pela administração Bolsonaro. Nesse sentido, ela pretende dar prioridade ao seguinte aspecto:

O Governo dará prioridade aos temas de segurança e defesa, com destaque para a segurança das fronteiras brasileiras e o combate aos crimes internacionais que afetam a vida de todos os brasileiros, como o narcotráfico e a corrupção. Será reforçada a cooperação em temas de segurança com os países vizinhos, em especial os membros do Mercosul. Em particular, será dada continuidade a iniciativas como o Foro Permanente de Segurança BrasilEUA e às reuniões dos mecanismos " $2+2$ " com os principais parceiros do Brasil em temas de defesa. [...] (Bolsonaro, 2019b)

Portanto, na passagem acima, fica claro que o tema de segurança nas fronteiras será estratégico e central na Política Externa Brasileira em âmbitos bilaterais e multilaterais. Vale lembrar que essa é uma ação iniciada na gestão anterior de Temer, com o Chanceler, José Serra, falando disso em maio de 2016. Em seguida, o seu sucessor, Aloysio Nunes, não apenas manteve a prioridade da temático, como 
aprofundou as ações acerca desse assunto com reuniões bilaterais com os vizinhos, assinatura de atos internacionais de combate aos crimes transnacionais com a Bolívia e a criação de medida administrativa nas embaixadas brasileiras na América do Sul para cuidar do assunto.

Ademais, ainda que o governo Bolsonaro esteja com um ano, cabe destacar a manutenção dos temas de agenda da Política Externa Brasileira entre os governos Temer e o atual. Como percebido, nos parágrafos anteriores, o processo de ideologização, comércio e segurança, são ações iniciadas pelos chanceleres José Serra e Aloysio Nunes. Mas mantidas pela administração do atual Chanceler, Ernesto Araújo.

No discurso de posse de Ernesto Araújo, no dia posterior, alguns apontamentos superficiais são abordados nessa direção. Em relação ao primeiro princípio de ideologização, o Chanceler empossado não explicitou em seu discurso, mas deixou claro quais países serão parceiros prioritários do Brasil, como EUA, Israel, Itália, Hungria, Polônia e "[...] países que se libertaram do Foro de São Paulo [...]" (Araújo, 2019), no caso, Argentina, Paraguai, Colômbia, Chile, etc. Portanto, de alguma forma, a ideia de "desideologização" percebidas em Serra e Nunes estão presentes em Araújo para manter algumas parcerias estabelecidas nos períodos anteriores, além de ampliar esse escopo com os países afins politicamente ao novo governo como italianos, poloneses e húngaros. Para comprovar que sua PEB não é mera palavra ao ar, entre os dias 01 e 02 de janeiro, o Ministro de Exteriores fez reuniões com EUA, Hungria, Polônia, Japão, Singapura, Chile, Portugal e Angola. Em todos os casos, em formato bilateral, houve diálogo acerca de potencializar o comércio.

Em sentindo muito próximo as ações de Serra e Nunes em relação à Venezuela, além de se posicionar claramente em rechaço aos "países do Foro de São Paulo", uma das suas primeiras concertações regionais foi articular um comunicado coletivo com mais 12 países (Argentina, Brasil, Canadá, Chile, Colômbia, Costa Rica, Guatemala, Guiana, Honduras, Panamá, Paraguai, Peru e Santa Lúcia), através do Grupo de Lima instituído na gestão Temer, com vistas a não reconhecer o novo governo de Nicolás Maduro (2019-2025). Essa ação se torna emblemática, pois é um dos primeiros atos do Ministro de Relações Exteriores empossado. Em consonância com a suspensão da 
Venezuela do MERCOSUL, é um dos momentos mais incisivos do distanciamento do Brasil para com o país vizinho. Portanto, observa-se que tanto no período Temer, quanto Bolsonaro, o discurso de desidelogização aparece para fazer uma crítica aos países do Sul aliados do Partido dos Trabalhadores (PT).

Vale mencionar o não reconhecimento do governo Nicolás Maduro em janeiro de 2019 pelo Brasil e Grupo de Lima. O foro, criado na gestão Nunes, tem sido o interlocutor dos países que pretendem se distanciar da Venezuela. Portanto, mais elemento real da estratégia de Política Externa que marca o processo de continuidade entre os governos Temer e Bolsonaro.

\section{CONSIDERAÇÕES FINAIS}

O presente texto fez uma Análise de Política Externa Brasileira dos governos Temer e Bolsonaro, no qual se defende as similaridades entre as administrações. Sem generalizar em todos os setores da ação internacional, encontraram-se semelhanças nos princípios e programas acerca da desideologização, do comércio e da segurança.

Em relação ao campo de estudo, a Análise de Política Externa é estudada desde os anos de 1940 em várias vertentes. Por sua vez, nos diversos estudos apresentados é fundamenta perceber o que fala Mendes (2015). Ele aponta três níveis de análise: ambiente externo, ambiente interno e ambiente ideológico.

Esse último campo, o ideológico, é fundamental para perceber que qualquer tomador de decisão possui uma escolha e um caminho. Logo, afirma-se que é improvável o fenômeno da desideologização, mas sim é uma estratégia discursiva para retirar a prioridade em países parceiros do PT, e buscar ocupar o espaço com os países chamados ocidentais (EUA, França, Inglaterra, Israel, etc.).

A Análise de Política Externa Brasileira nas gestões Serra, Nunes e Araújo, chegamse as seguintes argumentações. Na administração Temer, dividiu-se a análise em dois momentos com o período Serra (2016-2017) e Nunes (2017-2018). No primeiro momento, implantaram-se os novos princípios de Política Externa Brasileira, sendo que algumas ações começaram a desenvolver os discursos propostos. 
Em termos de desideologização ocorreu um progressivo distanciamento com a Venezuela e uma maior aproximação com países ocidentais como os EUA. As ações estiveram amparadas em notas individuais, coletivas e, também, no efetivo pedido de suspensão da Venezuela no MERCOSUL.

No aspecto comercial, axioma enfatizado por Serra, discutiu-se a necessária captação de investimentos e produção de acordos comerciais em formatos bilaterais. A abertura de negociação comercial com o EFTA é um exemplo dessa pretensão, bem como a aposta em finalizar o tratado de comércio com o México.

Por fim, a segurança nas fronteiras, princípio resgatado por Serra, produziu interações com os países limítrofes para uma profícua postura de combate ao crime organizado e aos crimes transnacionais em suas díades, sobretudo com a prospectiva criação de seminário sobre a temática.

O segundo momento foi percebido como estágio de aprofundamento dos princípios implantados após algumas iniciativas tímidas de Serra. Assim, em relação à linha de desideologização, criaram-se diversas ações e atitudes que concentraram muitos esforços do Itamaraty. Além de finalizar a suspensão da Venezuela do MERCOSUL, criaram-se articulações regionais via Grupo de Lima, dispositivo liderado pelo Brasil, para discutir como resolver as crises políticas no país vizinho. Ademais, o processo de distanciamento chegou à Nicarágua, onde foram feitas repetidas iniciativas de condenação de acontecimentos políticos internos daquele ente nacional.

A linha comercial se tornou mais complexa e prática com diversas iniciativas de aprofundamento da busca por investimentos e acordos comerciais. Percebeu-se amplo destaque para a abertura de negociações comerciais com países como Canadá, Colômbia, Coreia do Sul, Singapura. Além disso, as tentativas de acordo no EFTA seguiram sendo pauta central da PEB. Entretanto, o grande triunfo de Nunes foi conseguir finalizar acordo comercial com o Chile em 2018. Em paralelo, foram procurados acordos de investimentos nos vizinhos como a Guiana.

Por fim, o aspecto de segurança nas fronteiras se tornou mais prático a partir da criação de setor administrativo em todas as embaixadas sul-americanas para tratarem 
da temática. Também, foram finalizados acordos bilaterais com países limítrofes como a Bolívia para combater ilícitos transnacionais.

Na administração Bolsonaro, analisou-se o primeiro ano de Araújo (2019) na condução do Itamaraty. Esse momento é fundamental para o trabalho, porque sustenta os elementos de continuidade percebidos entre Serra e Nunes.

Na linha de desideologização, articulou-se maior distanciamento da Venezuela através do não reconhecimento do governo Maduro. Para conseguir efetivar essa ação, o Chanceler se utilizou do espaço criado pelo seu antecessor, Nunes, o agrupamento de Lima. No mesmo sentido, procurou manter o distanciamento da Nicarágua, utilizandose de repetidas notas individuais de condenação aos acontecimentos políticos daquele país.

Na pauta comercial, o processo de captação de investimentos e acordos comerciais segue como axioma. As negociações comerciais em curso com Canadá, Coreia, Colômbia, Singapura e EFTA, seguem sendo heranças do período anterior, e também apostas do governo atual. Ademais, destaca-se o processo de pedido de adesão a OCDE, como propostas mantidas de Temer, com a mudança na estratégia em se apoiar no peso estadunidense na instituição, aliado especial brasileiro.

Para finalizar, no aspecto de segurança nas fronteiras, as ações ainda são tímidas e pouco efetivas, mas focadas em discursos oficiais, já que é uma plataforma de campanha eleitoral do presidente.

A continuidade dos governos, Temer e Bolsonaro, foi analisada em três programas específicos de Política Externa que não refletem a totalidade de toda a ação internacional brasileira. Assim, elementos de descontinuidade são perceptíveis em muitos eixos, mas não foi o objetivo central desse artigo. Portanto, entende-se que as semelhanças estão nos essenciais princípios das duas administrações, sobretudo em enfatizar o necessário reposicionamento de parcerias bilaterais (menos países bolivarianos, mais países ocidentais), centralidade de esforços na pauta comercial (mais acordos comerciais e de investimentos) e combate ao crime organizado e aos crimes transnacionais através de segurança nas fronteiras. 


\section{REFERÊNCIAS BIBLIOGRÁFICAS}

Almeida, P. (2019). Miséria da diplomacia - A destruição da diplomacia no Itamaraty. Boa Vista: Editora UFRR.

Araújo, E. (2019). Discurso do ministro Ernesto Araújo durante cerimônia de Posse no Ministério das Relações Exteriores. Disponível em: http://www.itamaraty.gov.br/ptBR/discursos-artigos-e-entrevistas-categoria/ministrodas-relacoes-exterioresdiscursos/19907-discurso-do-ministro-ernesto-araujo-durantecerimonia-de-posse-noministerio-das-relacoes-exteriores-brasilia-2-de-janeiro-de-2019 [Acesso em: 23 jan. 2020].

Bolsonaro, J. (2019a). Discurso do Presidente da República, Jair Bolsonaro, durante Cerimônia de Posse no Congresso Nacional. Disponível em: http://www.itamaraty.gov.br/pt-BR/discursos-artigos-e-

entrevistascategoria/presidente-da-republica-federativa-do-brasil-discursos/19887discurso-dopresidente-da-republica-jair-bolsonaro-durante-cerimonia-de-posse-nocongressonacional-brasilia-1-de-janeiro-de-2019 [Acesso em 20 jan. 2020].

Bolsonaro, J. (2019b). Mensagem ao Congresso Nacional, 2019: 1a Sessão Legislativa Ordinária da 56ạ Legislatura. Disponível em http://www.casacivil.gov.br/centraldeconteudos/downloads/mensagem-ao-congresso-2019. [Acesso em 21 jan. 2020].

Cervo, A.; Bueno, C. (2015). História da política exterior do Brasil. 5ạ ed. rev. amp., Brasília: Editora Universidade de Brasília.

Echaide, J. (2016). Desideologización? La política exterior macrista desde uma visión critíca del análisis económico del derecho. Congresso de Relaciones Internacionales, 8, La Plata. Anais... pp. 1-18.

Mendes, P. (2015). "A raiz e o fruto na análise da política externa", Relações Internacionais, Lisboa, 16 (4), pp. 129-144. Disponível em: http://www.ipri.pt/images/publicacoes/revista_ri/pdf/ri16/RI16_10PEMendes.pdf [Acesso em: 19 Jan. 2020].

Neves, A.; Nunes, A. (2014). Diretrizes Gerais Do Plano de Governo. PSDB, pp. 1-69.

Nunes, A. (2017). Texto-base para o discurso de posse do Ministro de Estado das Relações Exteriores, Aloysio Nunes Ferreira. Disponível em [http://www.itamaraty.gov.br/pt-BR/notas-a-imprensa/15829-texto-base-paraodiscurso-de-posse-do-ministro-de-estado-das-relacoes-exteriores-aloysionunesferreira-palacio-itamaraty-7-de-marco-de-2017 [Acesso em 21 dez. 2019].

Salomón, M.; Pinheiro, L. (2013). "Análise de Política Externa Brasileira: trajetória, desafios e possibilidades de um campo de estudo". Rev. Bras. Polít. Int., 56 (1), pp. 4059. Disponível em: http://www.scielo.br/pdf/rbpi/v56n1/03.pdf [Acesso em: 21 Jan. 2020]. 
Saraiva, M. (2010). A diplomacia brasileira e as visões sobre a inserção externo do Brasil: institucionalistas pragmáticos $\mathrm{x}$ autonomistas. Mural Internacional, 1, pp. 45-52. Disponível

em: https://www.researchgate.net/publication/43601387_A_diplomacia_brasileira_e_as_vi soes_sobre_a_insercao_externa_do_Brasil_Institucionalismo_pragmatico_x_autonomis tas [Acesso em: 14 dez. 2019].

Serra, J. (2016). Discurso do ministro José Serra por ocasião da transmissão do cargo de ministro de estado das Relações Exteriores. Disponível em: http://www.itamaraty.gov.br/discursos-artigos-e-entrevistas-categoria/ministrodasrelacoes-exteriores-discursos/14038-discurso-do-ministro-jose-serra-por-ocasiaodacerimonia-de-transmissao-do-cargo-de-ministro-de-estado-das-relacoesexterioresbrasilia-18-de-maio-de-2016 [Acesso em 17 dez. 2019].

Sorato, D. (2019). A análise de política externa brasileira: A continuidade dos governos Temer e Bolsonaro. Monografia de Graduação, Relações Internacionais/Universidade Federal do Amapá.

Souza, A.; Souza, J.; Oliveira, T. (2016). Política Externa Brasileira: De Lula a Temer descontinuidades e progressos. International Relations Week, Bauru, Anais. Apresentação Oral.

Temer, M. (2016). Discurso do Presidente da República em exercício, Michel Temer, durante cerimônia de posse dos novos ministros de estado. Disponível em: http://www.itamaraty.gov.br/pt-BR/discursos-artigos-e-

entrevistascategoria/presidente-da-republica-federativa-do-brasil-discursos/14020discurso-dopresidente-da-republica-em-exercicio-michel-temer-durante-cerimonia-deposse-dosnovos-ministros-de-estado-brasilia-12-de-maio-de-2016 [Acesso em 11 jan. 2019].

\section{Fontes online}

Freixo, A. (2019). As relações exteriores - Bolsonaro, 100 dias. Le monde diplomatique, 10 de abril. Disponível em: https://diplomatique.org.br/as-relacoesexterioresbolsonaro-100-dias/. [Acesso em 28 jan. 2020].

Ruic, G. (2018). Governo Bolsonaro não trará ruptura à política externa, avalia Amado Cervo. Exame, 28 novembro. Disponível em: https://exame.abril.com.br/mundo/governo-bolsonaro-nao-trara-ruptura-apoliticaexterna-avalia-amado-cervo/. [Acesso em 20 jan. 2020]. 